\section{SMGrsup}

\section{SM Dermatology Journal}

\section{Article Information}

Received date: Jun 04, 2016

Accepted date: Jun 06, 2016

Published date: Jun 12, 2016

\section{*Corresponding author}

Jason Ramirez, Department of Family and Community Medicine, School of Medicine, University of Maryland, USA, Tel: 667-214-1841; Email: jramirez@ som.umaryland.edu

Distributed under Creative Commons CC-BY 4.0

\title{
A Woman with Hyperpigmentation of the Forehead
}

\author{
Jason Ramirez ${ }^{1 \star}$ \\ ${ }^{1}$ Department of Family and Community Medicine, School of Medicine, University of Maryland, USA
}

A 32-year-old woman presented with asymptomatic hyperpigmentation of her forehead cosmetically concerning to the patient. It worsened during summer months and lessened during the winter. It has been present for five years. Her medical history was significant for ADD managed with stimulants. She has been on the same estrogen/progesterone combination oral contraceptive for ten years. Physical examination revealed a tan, macular rash on forehead without raised borders or scale. Urine HCG was negative.

\section{Question}

Based on the patient's history and examination findings, which of the following is the most likely diagnosis?

A. Post-inflammatory hyperpigmentation

B. Melasma

C. Poikiloderma of Civatte

D. Drug- induced pigmentation.

\section{Discussion}

The correct answer is B: melasma. Melasma is a common disorder affecting over 5 million people in the United States [1]. Melasma is an acquired disorder of unclear etiology typically presenting as symmetrical hyperpigmentation of the face. Affected areas appear as light brown to dark brown macules and patches. Three clinical patterns have been described. The most common is the centrofacial pattern consisting of lesions on the forehead, cheeks, or chin. The malar pattern has lesions on the cheeks and nose. In the mandibular pattern, lesions are confined to the ramus of the mandible.

Melasma is more common in darker skin types. Other presumed risk factors include family history of melasma, exposure to UV light, pregnancy and oral contraceptives. In a study by Ortonne et al, $25 \%$ of women reported onset of melasma with oral contraceptive use [2]. UV light has been reported as a common exacerbating factor of melasma, secondary to UV light induced melanocyte proliferation.

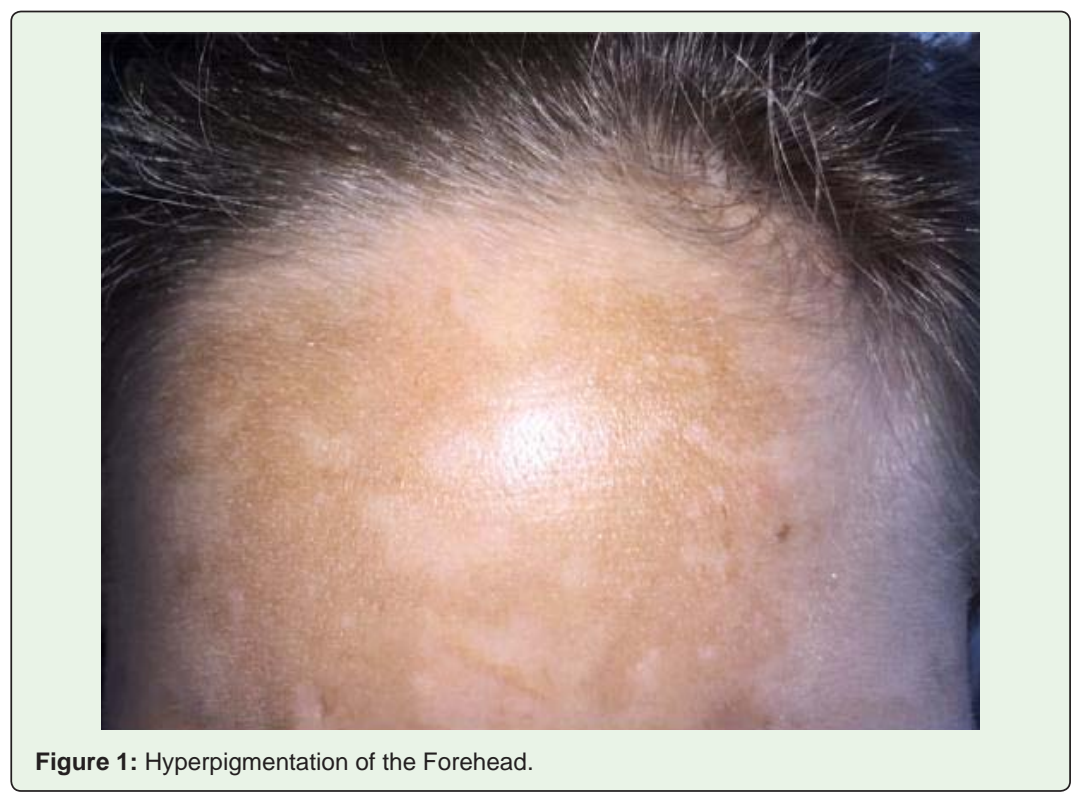


Post inflammatory hyperpigmentation occurs as a result of inflammatory injury to facial skin. Examples of conditions that may predispose to post-inflammatory hyperpigmentation include acne, contact dermatitis, eczema or superficial injuries.

Drug-induced hyperpigmentation involves hyperpigmentation that is generally more diffuse. Tetracyclines and amiodarone are common drugs that induce hyperpigmentation. The key to the diagnosis is the medication history.

Poikiloderma of Civatte is a condition characterized by mottled pigmentation changes and telangiectasias typically on the lateral neck with characteristic sparing of the submental area [3] (Figure 1).

\section{References}

1. Sheth VM, Pandya AG. Melasma: a comprehensive update: Part I. J Am Acad Dermatol. 2011; 65: 689-697.

2. Ortonne JP, Arellano I, Berneburg M, Cestari T, Chan H, Grimes P, et al. A global survey of the role of ultraviolet radiation and hormonal influences in the development of melasma. J Eur Acad Dermatol Venereol. 2009; 23: 1254-1262.

3. Katoulis AC, Stavrianeas NG, Panayiotides JG, Bozi E, Vamvasakis E Kalogeromitros D, et al. Poikiloderma of Civatte: a histopathological and ultrastructural study. Dermatology. 2007; 214: 177-182. 